\title{
Frequency of Kidney Stone in Population of Peshawar Coming to Northwest General Hospital Peshawar for Computed Tomography Scan (KUB)
}

\author{
Sadia Khattak, Spogmay Gulalay, Hoosae Pakhtoonkhwa \\ Department of Radiology, Northwest Institute of Health Sciences, Peshawar, Pakistan \\ Email address: \\ Spogmaygulalay@gmail.com (S. Gulalay)

\section{To cite this article:} \\ Sadia khattak, Spogmay Gulalay, Hoosae Pakhtoonkhwa. Frequency of Kidney Stone in Population of Peshawar Coming to Northwest \\ General Hospital Peshawar for Computed Tomography Scan (KUB). American Journal of Computer Science and Technology. \\ Vol. 4, No. 3, 2021, pp. 46-54. doi: 10.11648/j.ajcst.20210403.11
}

Received: July 27, 2021; Accepted: August 5, 2021; Published: August 27, 2021

\begin{abstract}
Aims: To find the Frequency of kidney stone in population of Peshawar coming to northwest general hospital. Material and Methods: This was Cross sectional examination done in North west General Hospital and Research center Peshawar during March to June 2019. Data were collected on a self-administer Questionnaire and analyzed using SPSS version 22. Results: From the study over a period (4 months) a total number of $100 \mathrm{CT}$ scan were done for finding kidney stones. Of these 64 patients having kidney stones and 36 were having no kidney stones. Among 64 patients 25 (37.3\%) were males patients and $39(58.2 \%)$ were female patients which are involved in the study. The most patients having kidney stones are under age of 35 to 50 years of age. Patients with right kidney stones were $44(65.7 \%)$ and left kidney stones were 29 (43.3\%). Conclusion: The final results of this study at have proven that urolithiasis indicates urinary tract stone involved number of factor. Selection of internal and external factors has an effect on the prevalence of disease in people. Female genders are more likely to developed kidney stone as compared to male. Computed tomography (CT) has been described because the "best imaging observe to verify the analysis of urinary stone," A situation so that it will arise in up to $12 \%$ of the population and continues to account for up to $50 \%$ of these patients.
\end{abstract}

Keywords: Prevelance, Kidney Stone, Computed Tomography, Urolithasis, Incidence, Frequency, Nephrolithiasis

\section{Introduction}

The formation of kidney stone involves a numbers of factors such as environmental and genetic elements. In many countries of the western, the occurrence and frequency of kidney stone formation were said to be $2 \%$ to $19 \%$, with a high rate among men [1] In Asia one of the most accepted urological diseases is kidney stone. The incidence and configuration of stones worldwide vary, and there are many changes at the end time, with incidence starting from $7 \%$ to thirteen $\%$ in North the United States, in Europe its 5\% to 9\%, and in Asia 1\% to 5\% [2]. Changes amongst nations reveal some harmful factors, along with grow old, sex, nutritional behavior, fluid consumption, weather, career and training stage, fame, cultural or countrywide division, inherited and metabolic sicknesses [3].

Kidney stone also called nephrolithiasis is common place problems worldwide, with a frequency of $7 \%$ within the adults, and $\geq 30 \%$ recurrence rate within 10 years. The occurrence of kidney stones is globally growing with an expected frequency ranging up to $15 \%$ all through lifetime, about $7 \%$ of women and $13 \%$ [4] of men will broaden a kidney stone. Calcium oxalate is the most common place stone for the duration of the Europe.

In United States the kidney stone frequency has multiplied since 1964-1972 term and seems to have balanced out for the mid 1980 [5]. Global increases in prevelance are in Germany, Spain, Italy. Scotland have slightly decreased from $3.83 \%$ in 1977 to $5.0 \%$ in 1987 . In Asia approximately $1-19 \%$ of population suffered from kidney stone [6]. Demographically Asia can be separated into East Asia, primary Asia, West Asia, North Asia, Southeast Asia and South Asia Prevelance of kidney stone is in West Asia, South Asia and Southeast Asia 5 5\% [7]. In India the population is $12 \%$ of them are 
estimated to have urinary stone and determine of which $50 \%$ can be come to be with renal failure. Kidney stone is most vital sickness in Pakistan the prevalence $(100,000)$ within the north range from 2.4 in Chitral to $9.4 \%$ in Gilgit Across Pakistan the incidences ranges from $7.4 \%$ in north $28 \%$ in west to 200 consistent with 100000 in the south [8].

Kidney stones are hard crystalline minerals formed in the kidneys or urinary tract. Kidney stones are a common cause of blood (hematuria) in the urine and are usually severe pain in the abdomen, side or groin. Kidney stones are sometimes called kidney stones. A condition with kidney stones is called a kidney stone [9]. Anyone who can develop kidney stone, but with certain disease and condition or those taking certain medications are more likely to develop kidney stones. In male the kidney is more common than female. Most kidney stones formed in individuals between the ages of 20 and 49, and the individuals who have numerous kidney stones in there are susceptible to build up the primary stone in the next stage of life [10]. A person who have of kidney stones in their family is also a risk factor for kidney stones. Asians and Caucasians than Native Americans, Africans or African Americans people the kidney stone are more common [11]. Few pregnant females have kidney stones, and there is proof that changes identified with pregnancy may expand the danger of stone development. Elements that can add to the development of stones during pregnancy incorporate diminished urine due to increased progesterone levels and reduced fluid intake due to the reduced capacity of the enlarged uterine bladder. Urinary calcium excretion in healthy pregnant women will also increase slightly [12].

If you have certain diseases, humans are more likely to develop kidney stones, such as: persistent or persistent urinary tract obstruction, bladder stimulation, cystic nephropathy, cystineuria, digestive system disease or gastrointestinal surgery History, gout, hypercalciuria, hyperglycemia, hyperuricemia, weight problems, recurrence or recurrence, urinary tract infections, renal tubular acidosis [13]. If you take one or more medications over a period of time, the time for kidney stones is more likely to increase:

1) Diuretics,

2) Calcium-based totally antiacid.

3) Indinavir,

4) Toperamide [14].

When urine excretion is decreased and there is extra stone forming substance within the urine than the chances of kidney stone formation is high. Reduced fluid intake cause dehydration or exhausting exercise without good enough fluid increases the possibility of kidney stones. Difficulty in urine can also cause stone formation; weather can be a chance for kidney stone formation, seeing that people of warm and waterless regions are much more likely to emerge as dehydrated and at risk of stone development [15]. Kidney stones can also ultimately be attributed to contamination within the urinary tract. These are called struvite or contaminated stone. Metabolic abnormalities, including innate metabolic problems, can regulate urine composition and the risk of individual stones [16]. At the same time as a few renal calculi may not produce symptoms (called "silent" stones), humans who have kidney stones regularly report the surprising onset of sharp, cramping ache in their low again and/or facet, groin, or stomach. The severity of pain in the abdomen, groin and / or lower back is usually waxy and weakened, which is characteristic of severe pain (this pain is sometimes called renal colic) [17]. It can be so severe that nausea and vomiting often occur. Many people describe this pain as the most severe pain in their life, even more severe than the pain of childbirth or bone damage [18].

When infection occurs due to kidney stone it may cause blood in the urine or either fever, chill may also present. When it occurs, due to kidney stones, there may be signs of dysuria, urgency, pain in the penis or testicular pain [19]. Complications of kidney stones are uncommon if you seek treatment from a health care expert earlier than problems occur [20]. If kidney stones aren't dealt with, they could reason:

1) Hematuria or blood in the urine.

2) Severe pain.

3) UTIs, inclusive of kidney infections.

4) Loss of kidney function.

Kidney stones may be as small as a grain of sand or as large as a pearl [21]. They could live in kidneys or journey via ureters (the tubes that pass from your kidneys to bladder), and out with urine. When a kidney stone moves through ureters and out urethra with urine, it's far referred to as passing a kidney stone. A kidney stone also caught in urinary tract and block urine from getting through. All types of kidney stones are not composed of the identical minerals. Specific kinds of nephrolithiasis contain: The most common kidney stone are calcium stone. They are formed by calcium oxalate and calcium phosphate.

People who eat less oxalate food have low chance of calcium oxalate stone formation. Food that contains excessive oxalate includes:

1) Potato chips.

2) Peanuts.

3) Chocolate.

4) Beets.

5) Spinach.

6) Uric acid stone is more common in men than in women [22].

Uric acid stone common in people who have gout or the ones done chemotherapy. Uric acid stone is formed when acid concentration in urine is high. An eating food have high purines can increase acidic level in urine. Purine is a colorless material present in animal proteins, consisting of fish, shellfish, and meats [23]. Struvite stone is determined primarily in female with infection in urinary tract. These calculi may be massive and source of obstruction in urine. Cystine types of kidney stones are uncommon. They are common in each females and males who have the inborn disease cystinuria [24]. In cystine stone a natural acid is formed inside the body and flow from the kidney into the urine.

Kidney stones diagnosis calls for a complete health records 
assessment and a bodily examination. Different checks include: examination of blood to check the level of calcium, phosphorus, uric acid, and electrolytes, test to determine blood urine nitrogen (BUN) and creatinine test for kidney functioning, Urine analysis test for crystals, passed stones examination to rule out their types [25]. The following investigations can exclude obstruction:

1) Abdominal $x$-ray.

2) Intravenous pylogram.

3) Retrograde pyelogram.

4) Ultrasound of the kidney (the preferred test).

5) MRI scan of the abdomen and kidneys.

6) CT scan (KUB) [26].

The contrast which is used in CT scan and the IVP can disturb kidney function. If the individual have normal kidney function contrast CT scan is not required. Computed tomography (CT) is defined as "the first imaging test that confirm urinary stones [27], which makes it appear in up to $12 \%$ of the population and continues to account for up to $50 \%$ of these patients: CT scan plays a crucial role in many clinical applications, including flank pain evaluation, urinary stone monitoring, etc. [28]. Recent estimates estimate that this amount of radiation can also cause additional malignant neoplasia at 1400 from 500 .

Without contrast CT (KUB) is best suited for imaging ureteral stones, with the majority (99\%) radiopaque. Scanning the patient in prone position is preferred because it provides information on whether a stone is inside the ureterovesical junction [29] remains met or whether he has freely entered the urinary bladder. A stone will pass continuously and settle next to the anterior urinary bladder wall as soon as it is miles away from the ostium in a susceptible patient.

Alternatively, some centers may "turn" the affected person and rescan the pelvis if: The stone is identified at the base of the ureterovesical junction / bladder in the spinal scan [30]. The choice often depends on the supervision of the register and the group of workers involved.

CT KUB may also have secondary signs of obstruction in urine, including ureterohydronephrosis and prenephric strands [31]. In patients with low pelvic fat, it may be difficult to distinguish a ureteral stone from a phlebolith. Two beneficial signs were detected:

Cometail Signal: indicates a phlebolith.

Tender Tissue Rim Sign: shows a urethral stone [32].

Aims and Objectives

The General objective of the study is:

To find the Frequency of kidney stone in population of Peshawar coming to Northwest General Hospital Peshawar.

\section{Material and Methods}

\subsection{Study Design}

Cross-sectional Study.

\subsection{Study Settings}

Northwest General Hospital Peshawar.

\subsection{Study Duration}

04 Months.

\subsection{Sample Size}

Sample size is calculated on Raosoft software. Calculated sample size was 100 with margin of error $9.8 \%$ and confidence interval $95 \%$.

http://www.raosoft.com/samplesize.html

\subsection{Sampling Technique}

Convenient sampling technique.

\subsection{Sample Selection}

\subsubsection{Inclusion Criteria}

The study will include all patients who are referred by physician for the complains of flank pain for CT scan KUB of both genders (male and female).

\subsubsection{Exclusion Criteria}

Patient who are unconsciousness.

\subsection{Statistical Analysis}

Data is presented in the form of graphs such as bar graph, pie chart etc. Version 22 of the social science statistics package (SPSS) is used for data analysis. Data were viewed in SPSS. Descriptive statistic was run on data. Frequency are found and shown in the form of bar charts. Categorical data was presented in the form of pie charts.

\section{Results}

The study was done at Northwest General Hospital Peshawar, Radiology department. The study population comprised of CT KUB patients. $100 \mathrm{CT}$ SCAN was carried out during my study duration. The Radiology unit of North west General Hospital comprises of three radiographers and in two Functioning machine. (As noted from the radiology department records for 4 months from March to June 2019).

From the study over a period (4 months) a total number of $100 \mathrm{CT}$ scan were done for finding kidney stones. Of these 64 patients having kidney stones and 36 were having no kidney stones. Among 64 patients 25 (37.3\%) were males patients and $39(58.2 \%)$ were female patients which are involved in the study. The most patients having kidney stones are under age of 35 to 50 years of age. Patients with right kidney stones were $44(65.7 \%)$ and left kidney stones were $29(43.3 \%)$.

Patients with single right kidney stone were 24 (35.8\%), single left kidney stones were 15 (22.4\%), both kidneys having single stone were $16(23.9 \%)$, multiples stones in right kidney were $4(6.0 \%)$, multiples stones in left kidney 3 (4.5\%), and both kidney having multiples stones were 2 


\section{$(3.0 \%)$}

Patients involved in the study having stone in the right renal pelvis were $25(37.3 \%)$, stone in the left renal pelvis were $4(6.0 \%)$, right ureter $17(25.4 \%)$, left ureteric stone were $5(7.5 \%)$, right vesicoureteric stone $4(6.0 \%)$, left vesicoureteric stone $1(1.5 \%)$ and urinary bladder stone 8 $(11.9 \%)$ were found in the participant involved in the study.

Male patients involved in the study were $25(37.3 \%)$, among 25 male patients $20(80.0 \%)$ patients have right kidney stones and $5(20.0 \%)$ patients have left kidney stones. $14(56.0 \%)$ male patients having single right kidney stone, single left kidney stones patients were 6 (24.0\%), both kidney having single stone $4(16.0 \%)$, multiples stones in right kidney was $1(4.0 \%)$ of patients.
Numbers of female patients were $39(58.2 \%)$. of these 39 female patients $25(64.1 \%)$ having right kidney stones and 14 $(35.8 \%)$ were left kidney stone. Female patients with single right kidney stones were 10 (25.6\%), single left kidney stone $9(23.1 \%)$, both kidney having single stone were $12(30.8 \%)$, multiples stones in right kidney were $3(7.7 \%)$, multiples stones in left kidney $3(7.7 \%)$, both kidney having multiples stones was $2(5.1 \%)$.

Female patients with stones right renal pelvis $18(46.2 \%)$, left renal pelvis $3(7.7 \%)$, right ureteric stone $7(17.9 \%)$, left ureter $4(10.3 \%)$, stone in the urinary bladder were $4(10.3 \%)$, right VUJ stone $2(5.1 \%)$ and left VUJ stones 1 (2.6\%).

Analysis.

Table 1. Shows frequency and percentage of Gender wise distribution.

\begin{tabular}{llllll}
\hline Male and Female & & & & Calid Percent & Cumulative Percent \\
\hline & & Frequency & Percent & 39.1 & 39.1 \\
\multirow{3}{*}{ Valid } & Male & 25 & 37.3 & 60.9 & 100.0 \\
& female & 39 & 58.2 & 100.0 & \\
\hline
\end{tabular}

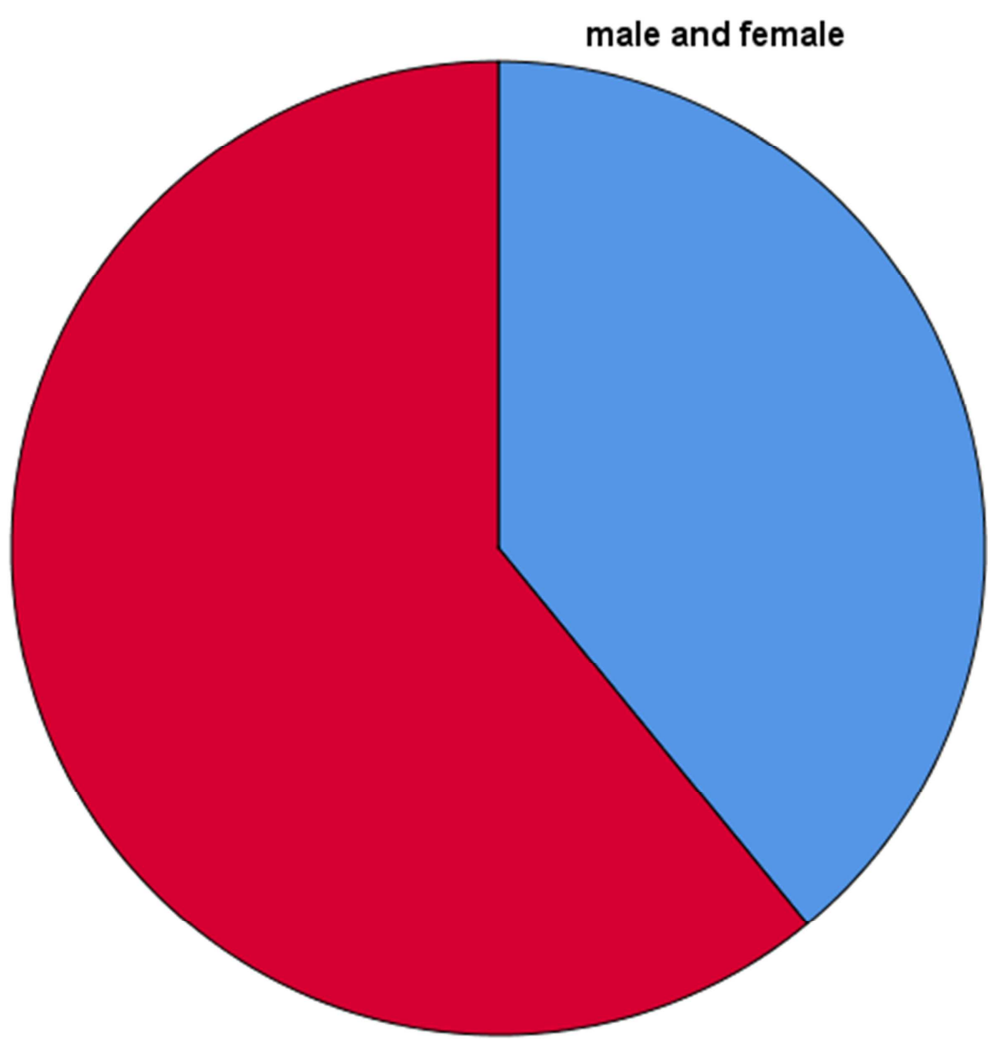

Figure 1. Shows distribution of male and female in the study.

Table 2. Age wise distribution of participant involved in the study.

\begin{tabular}{|c|c|c|c|c|c|}
\hline \multicolumn{6}{|c|}{ age in years } \\
\hline & & Frequency & Percent & Valid Percent & Cumulative Percent \\
\hline \multirow{6}{*}{ Valid } & 5 to 20 years & 8 & 11.9 & 12.5 & 12.5 \\
\hline & 20 to 35 years & 21 & 31.3 & 32.8 & 45.3 \\
\hline & 35 to 50 years & 22 & 32.8 & 34.4 & 79.7 \\
\hline & 50 to 65 years & 9 & 13.4 & 14.1 & 93.8 \\
\hline & 65 to 80 years & 4 & 6.0 & 6.3 & 100.0 \\
\hline & Total & 64 & 95.5 & 100.0 & \\
\hline
\end{tabular}




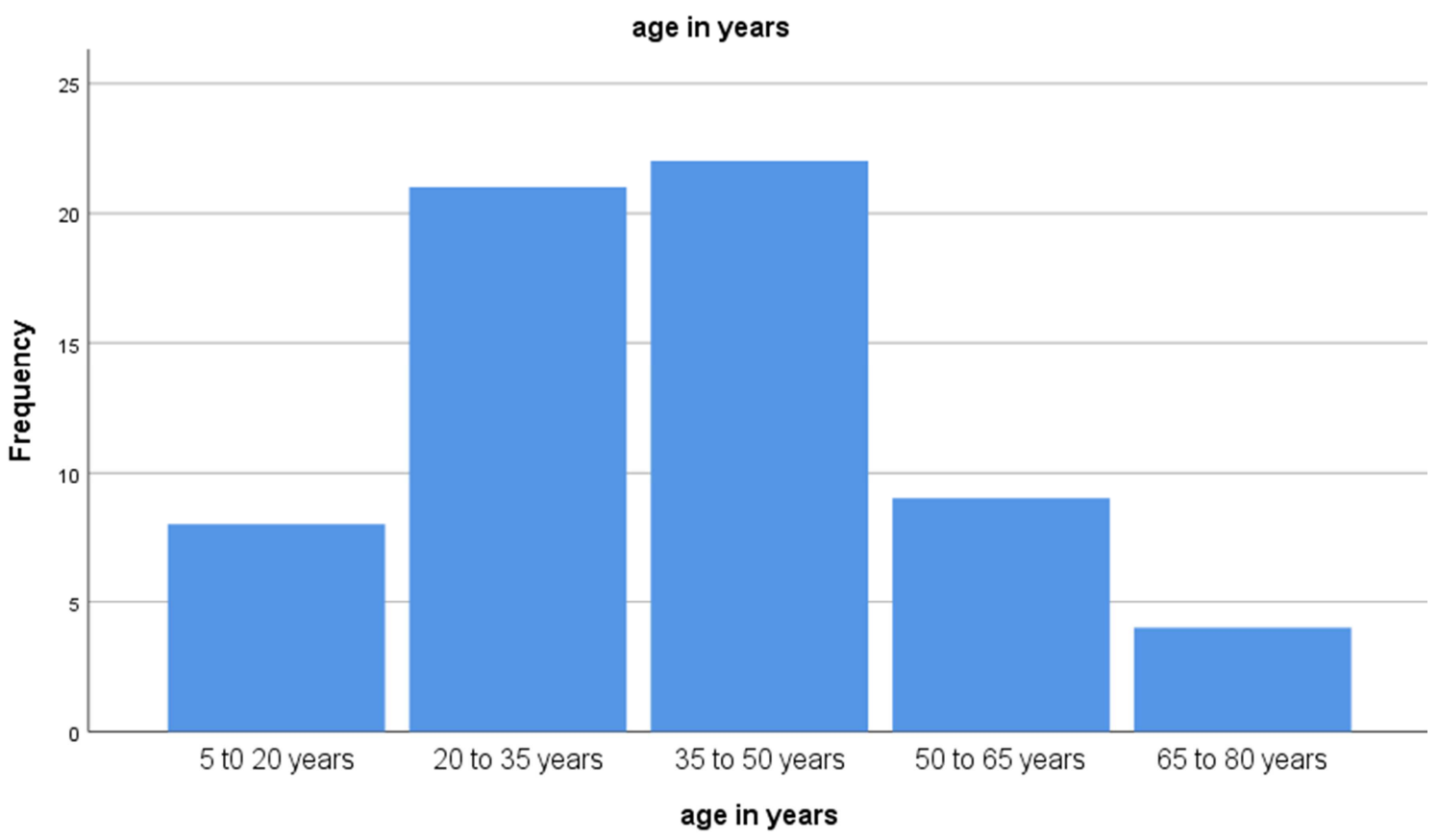

Figure 2. Age wise distribution of patients which is heighest in 35 to 50 years of age.

Table 3. Shows frequency and percentage of left kidney stone of patients.

\begin{tabular}{llllll}
\hline \multicolumn{2}{l}{ left kidney stones } & & & & \\
\hline & & Frequency & Percent & Valid Percent & Cumulative Percent \\
\hline \multirow{3}{*}{ Valid } & No & 35 & 52.2 & 54.7 & 54.7 \\
& Yes & 29 & 43.3 & 45.3 & 100.0 \\
& Total & 64 & 95.5 & 100.0 & \\
\hline
\end{tabular}

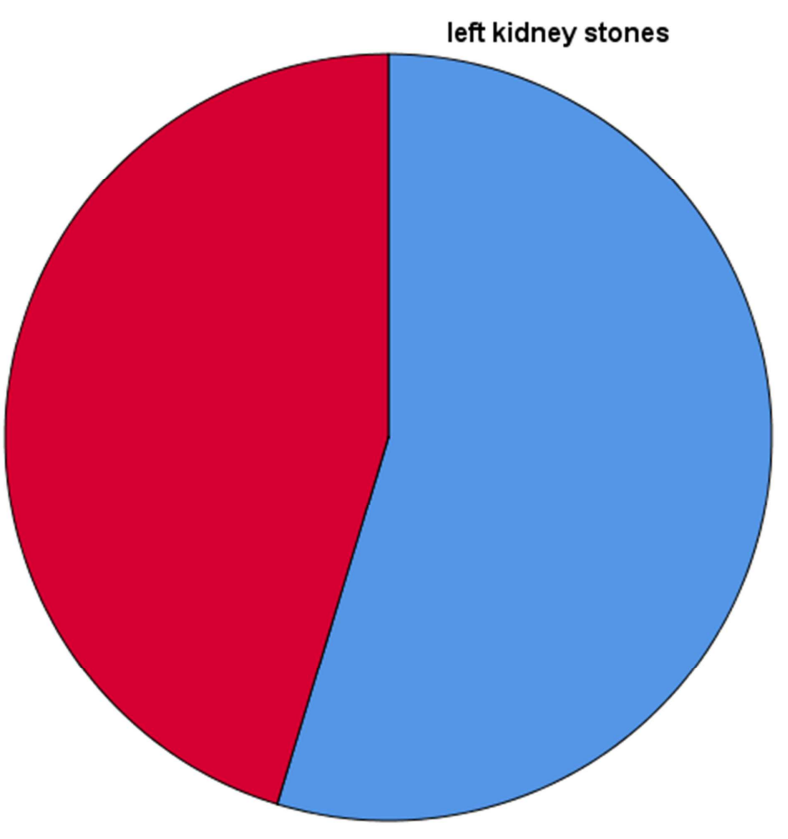

Figure 3. Shows patients with left kidney stones.

Table 4. Shows 44 patients having right kidney stones.

\begin{tabular}{llllll}
\hline \multicolumn{2}{l}{ right kidney stones } & & & & Cumulative Percent \\
\hline \multirow{2}{*}{ Valid } & & Frequency & Percent & Valid Percent & 31.3 \\
& No & 20 & 29.9 & 31.3 & 100.0 \\
& Yes & 44 & 65.7 & 68.8 & 100.0 \\
\hline
\end{tabular}




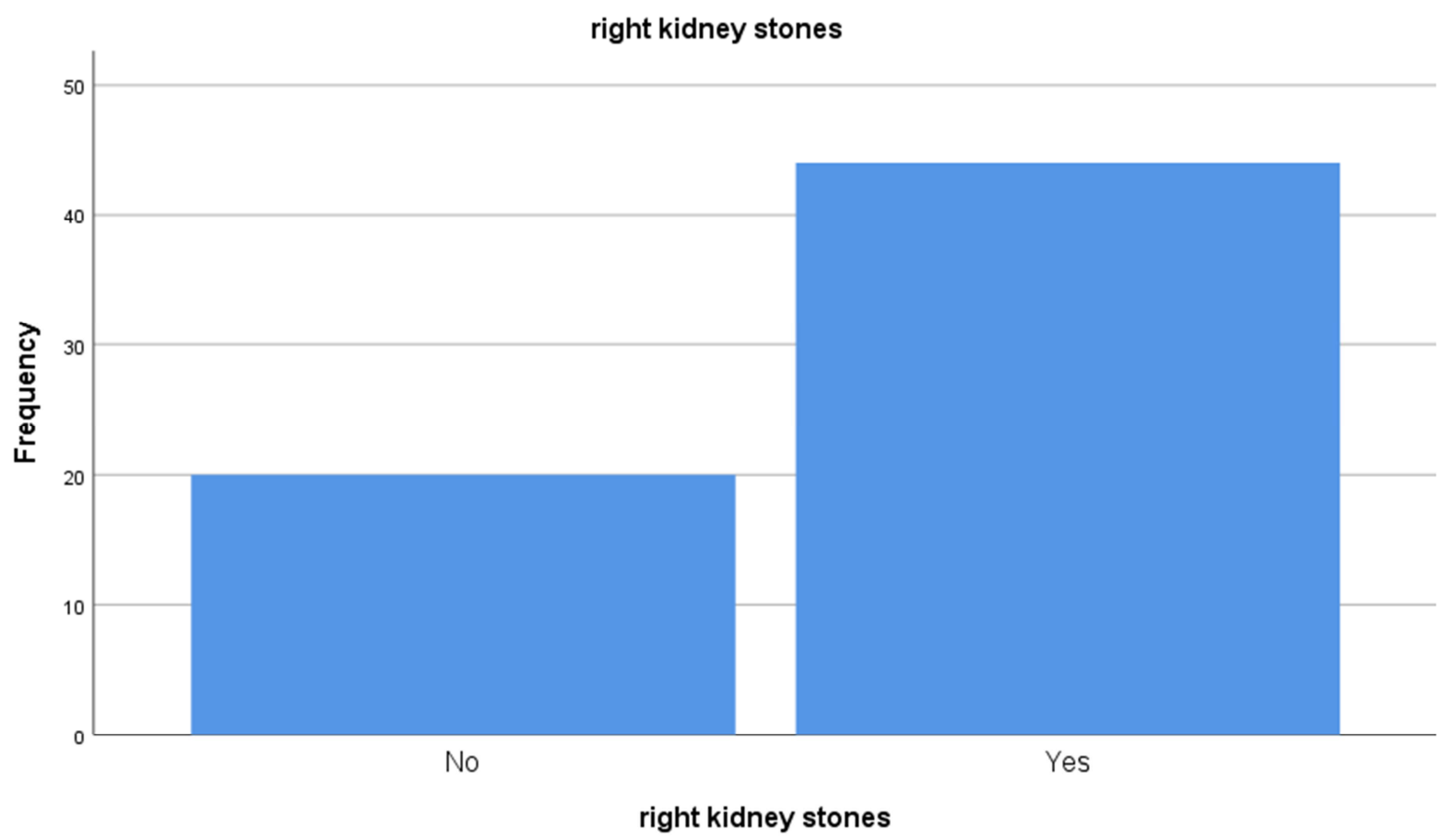

Figure 4. Right kidney stone patients.

Table 5. Numbers of stones.

\begin{tabular}{|c|c|c|c|c|c|}
\hline \multicolumn{6}{|c|}{ Numbers of stones } \\
\hline & & Frequency & Percent & Valid Percent & Cumulative Percent \\
\hline \multirow{7}{*}{ Valid } & single right kidney stone & 24 & 35.8 & 37.5 & 37.5 \\
\hline & single left kidney stone & 15 & 22.4 & 23.4 & 60.9 \\
\hline & both kidney having single stone & 16 & 23.9 & 25.0 & 85.9 \\
\hline & multiples stones in right kidney & 4 & 6.0 & 6.3 & 92.2 \\
\hline & multiples stone in left kidney & 3 & 4.5 & 4.7 & 96.9 \\
\hline & both kidney having multiples stone & 2 & 3.0 & 3.1 & 100.0 \\
\hline & Total & 64 & 95.5 & 100.0 & \\
\hline
\end{tabular}

numbers of stones

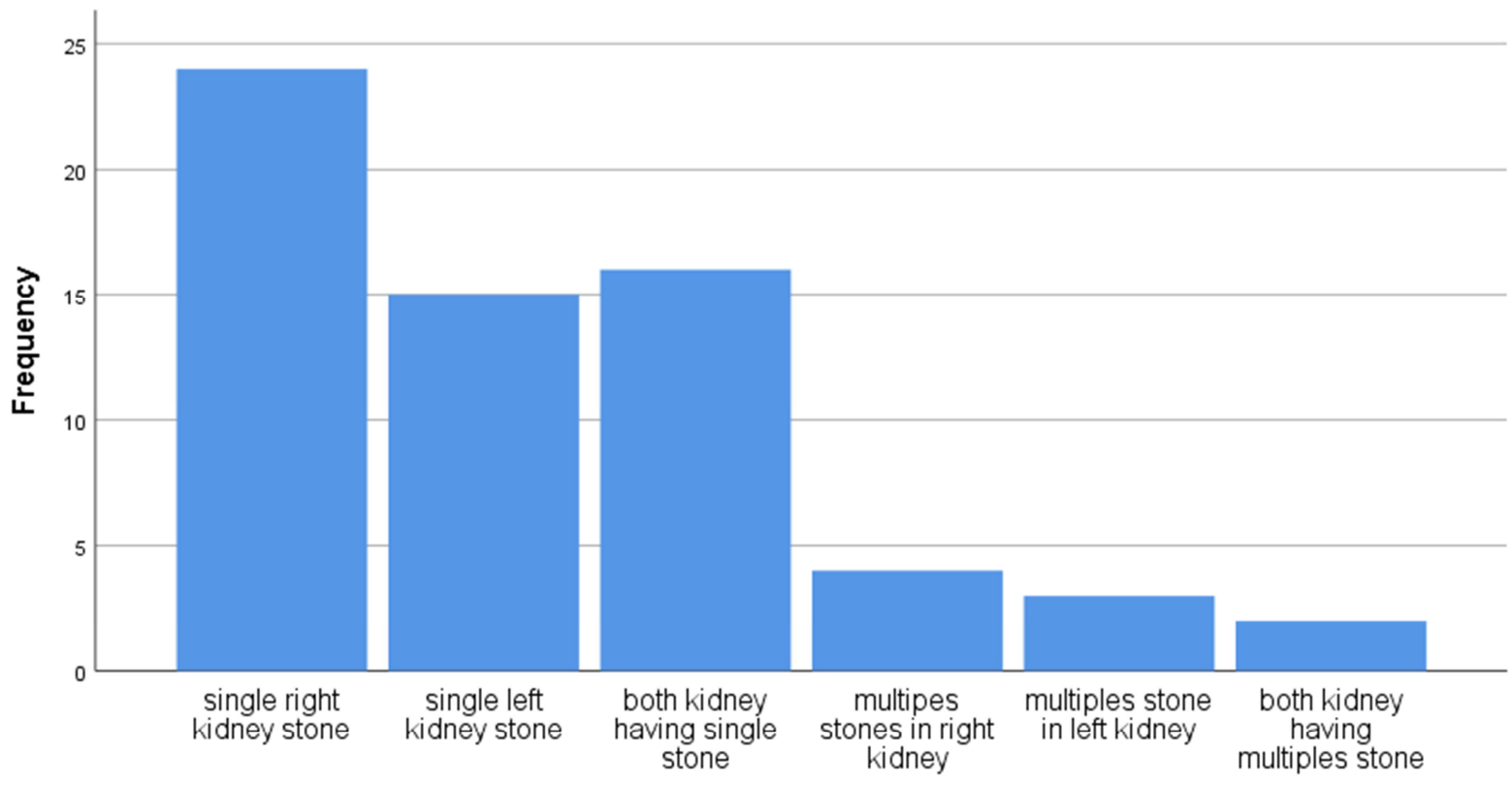

numbers of stones

Figure 5. Shows numbers of stone in both kidneys. 
Table 6. Location of kidney stone in patients which is highest in right renal pelvis.

\begin{tabular}{llllll}
\hline location of kidney stones & & & & \\
\hline & & Frequency & Percent & Valid Percent & Cumulative Percent \\
\hline \multirow{6}{*}{ Valid } & right renal pelvis & 25 & 37.3 & 39.1 & 39.1 \\
& left renal pelvis & 4 & 6.0 & 6.3 & 45.3 \\
& right ureter & 17 & 25.4 & 26.6 & 71.9 \\
& left ureter & 5 & 7.5 & 7.8 & 79.7 \\
& urinary bladder & 8 & 11.9 & 12.5 & 92.2 \\
& right vesicoureteric junction & 4 & 6.0 & 6.3 & 98.4 \\
& left vesicoureteric junction & 1 & 1.5 & 1.6 & 100.0 \\
& Total & 64 & 95.5 & 100.0 & \\
\hline
\end{tabular}

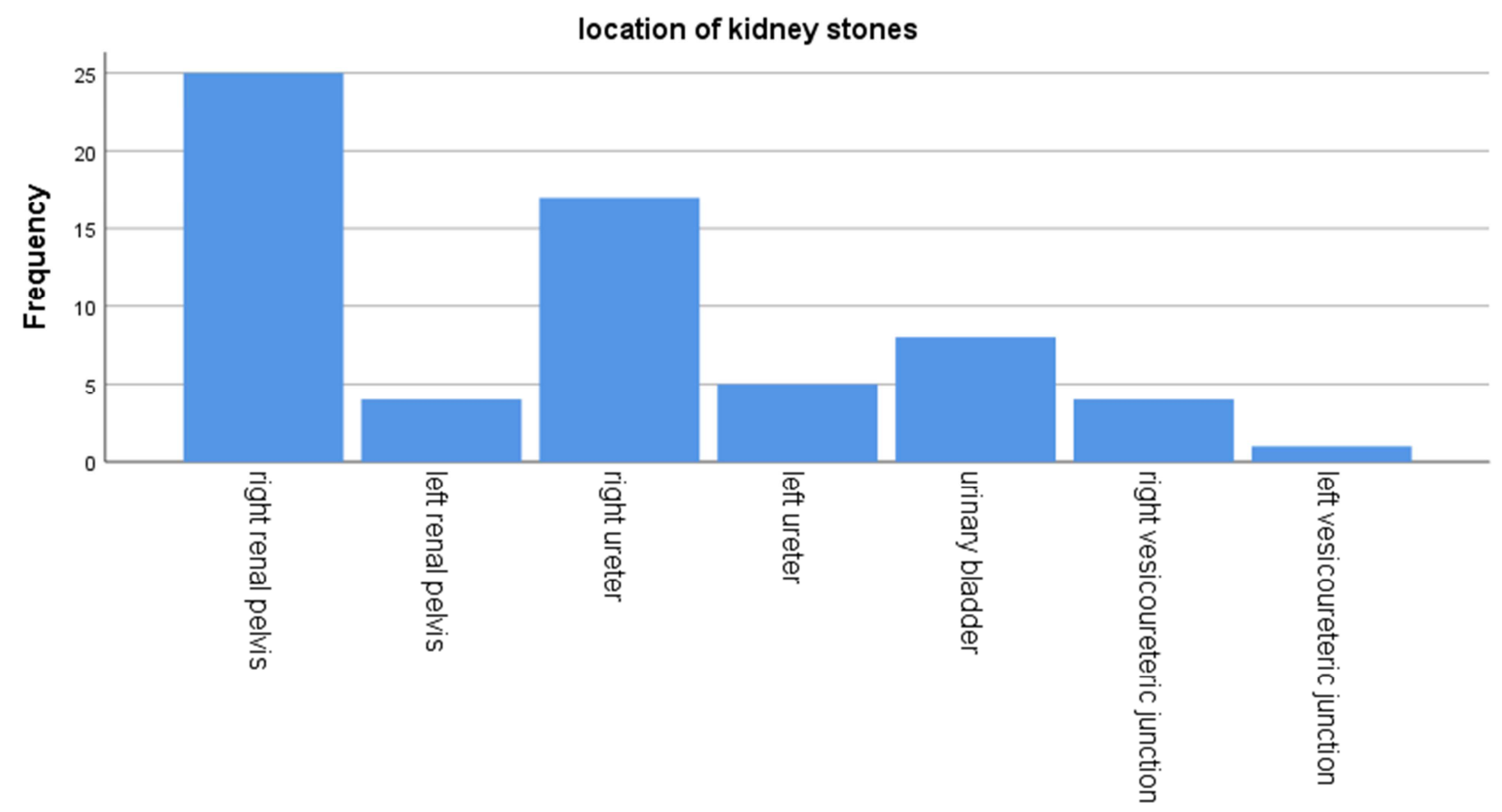

location of kidney stones

Figure 6. Location of kidney stone of patients.

\section{Discussion}

Nephrolithiasis torments and annoys humanity for several centuries. Pakistan and other countries in the world, the conversion of urinary bladder stone to the other urinary tract stone is steadily increasing. Pakistan is one of the countries wherever the occurance of this disease is high [10].

Ogata et al 6. Have carried out a study in which kidney stones were found mainly in the 3 rd and 4th decade of lifecycle. The outcomes are comparable to our study, in the most patient between 35 and 50 years old was [15].

In 1996, Smith et al The seminal paper that helped in the age of CT as a first-line test for kidney stones, and reported results from 292 consecutive CT scan of the patients with the symptoms of acute flank pain. He obtained urolithasis in CT scan of the $34 \%$ of the patients and in $10.3 \%$ of the CT scan he found abnormalities, which are not related to stone disease. Our study includes $100 \mathrm{CT}$ scans during study duration, in which $64 \%$ patients had kidney stones and 36\% were not having kidney stones [23].
Limitation of the study

This investigation has numerous restrictions and the results must be taken with caution. First, the study sample may not be descriptive of the inhabitants because of the convenient sampling techniques of undertakes. Second, the sample size is small which control the possible useless result. Third, the cause and effect relationship between the involved factors and formation of kidney stone could not be presented due to crosssectional study. Finally, women remained overrepresented in the sample survey as many men had been travelling people and frequently worked in different towns.

\section{Conclusion}

The Frequency of the kidney stone in current study sample of the selected tertiary care hospital of Peshawar NWGH. Female gender is more likely to developed kidney stone as compared to male. CT scan has been defined "best imaging test to confirm the diagnosis of kidney stone". The computed 
tomography scan plays an important role in a number of clinical conditions such as the assessment of flank pain, urolithiasis monitoring, etc.

\section{Recommendation}

Further study is needed on a large scale to find out to frequency of kidney stone in population of KPK because of mineralized water coming from mountain ranges. The dietary habits of population of KPK include tomato in their diet that may be the cause of calcium oxalate kidney stones.

\section{References}

[1] Jel, lison FC. Smith JC, Heldt JP, Spengler NM, Nicolay LI, Ruckle HC et al. Effect of low dose radiation computerized tomography protocols on distal ureteral calculus detection. J Urol 2009; 182 (6): 2762-7.

[2] Catalano O, Nunziata A, Sandomenico F, Siani A. Acute flank pain: comparison of unenhanced helical CT and ultrasonography in detecting causes other than ureterolithiasis. EmergRadiol 2002.

[3] Bariol SV, Tolley DA. What is the best imaging for stone management? BJU Int 2005; 95: 4-5.

[4] Chin M, Mendelson R, Edwards J, Foster N, Forbes G. Computed tomographic colonography: prevalence, nature, and clinical significance of extracolonic findings in a community screening program. Am J Gastroenterol 2005; 100: $2771-2776$

[5] Curhan GC, Willett WC, Rimm EB, et al: Body size and risk of kidney stones. J Am SocNephrol 9: 1645-1652, 1998.

[6] Poletti PA, Platon A, Rutschmann OT, et al. Lowdose versus standard-dose CT protocol in patients with clinically suspected renal colic. AJR Am J Roentgenol. 2007; 188: 92733.

[7] Ha M, MacDonald RD. Impact of CT scan in patients with first episode of suspected nephrolithiasis. J Emerg Med. 2004; 27: $225-31$.

[8] Katz SI, Saluja S, Brink JA, Forman HP. Radiation dose associated with unenhanced CT for suspected renal colic: impact of repetitive studies. AJR Am J Roentgenol. 2006; 186 $1120-4$.

[9] Kocher KE, Meurer WJ, Fazel R, et al. National trends in use of computed tomography in the emergency department. Ann Emerg Med. 2011; 58: 452-62.

[10] Graham A, Luber S, Wolfson AB. Urolithiasis in the emergency department. Emerg Med Clin N Am. 2011; 29: 519-38.

[11] Coursey CA, Casalino D, Remer EM, et al. American College of Radiology appropriateness criteria: acute onset flank pain suspicion of stone disease. Ultrasound Q. 2012; 28: 227-33.

[12] Katz DS, Scheer M, Lumerman JH, et al. Unenhanced helical computed tomography for suspected renal colic: experience with 1000 consecutive examinations. Urology. 2000; 56 (1): 53-57.
[13] Ather MH, Faizullah K, Achakzai I, Siwani R, Irani F. Alternate and incidental diagnoses on noncontrast-enhanced spiral computed tomography for acute flank pain. Urol J. 2009; 6: 14-18.

[14] Ahmad NA, Ather MH, Rees J. Incidental diagnosis of diseases on un-enhanced helical computed tomography performed for ureteric colic. BMC Urol. 2003; 3: 1-6.

[15] Qaseem A, Dallas P, Forciea MA, Starkey M, Denberg TD; Clinical Guidelines Committee of the American College of Physicians: Dietary and pharmacologic management to prevent recurrent nephrolithiasis in adults: A clinical practice guideline from the American College of Physicians. Ann Intern Med 161: 659-667, 2014.

[16] Goldfarb DS, Fischer ME, Keich Y, Goldberg J: A twin study of genetic and dietary influences on nephrolithiasis: A report from the Vietnam Era Twin (VET) Registry. Kidney Int 67: 1053-1061, 2005.

[17] Saigal CS, Joyce G, Timilsina AR; Urologic Diseases in America Project: Direct and indirect costs of nephrolithiasis in an employed population: Opportunity for disease management? Kidney Int 68: 1808-1814, 2005.

[18] Edvardsson VO, Goldfarb DS, Lieske JC, Beara-Lasic L, Anglani F, Milliner DS, Palsson R: Hereditary causes of kidney stones and chronic kidney disease. PediatrNephrol 28: 1923-1942, 2013.

[19] Pearle MS, Calhoun EA, Curhan GC (2005) Urologic Diseases in America project: Urolithiasis. J Urol 173: 848857.

[20] Soucie JM, Coates R, McClellan W, Austin H, Thun M (1996) Relation between geographic variability in kidney stones prevalence and risk factors for stones. Am J Epidemiol 143: 487-495.

[21] Trinchieri A, et al. (2000) Increase in the prevalence of symptomatic upper urinary tract stones during the past 10 years. EurUrol 37: 23-25.

[22] Stamatelou KK, Francis ME, Jones CA, Curhan GC (2003) Time trends in reported prevalence of kidney stones in the United States: 1976-1994. Kidney Int 63: 1817-1823.

[23] Brikowski T, Lotan Y, Pearle M (2007) A Painful Truth: Climate Change Will Increase Kidney Stone Disease (GeolSoc America, Denver).

[24] W Hochreiter, T Knoll, B Hess. Pathophysiology, diagnosis and conservative therapy of non-calcium kidney calculi. Ther Usmach 2003; 60 (2): 89-97.

[25] KH Bichler, E Eipper, K Naber. Infection induced urinary stones. Urologe A. 2003; 42 (1): 47-55.

[26] Rajput PA, Saadat K, Khan Din S, Nawaz Haq MS. Present trend of urolithiasis in Baluchistan: A single centre experience. J CollPhysSurg Pak. 2002; 12 (10): 615-22.

[27] Kim H, Jo MK, Kwak C, Park SK, Yoo KY, Kang D, et al. Prevalence and epidemiologic characteristics of urolithiasis in Seoul, Korea. Urology 2002; 59: 517e21.

[28] Yasui T, Iguchi M, Suzuki S, Kohri K. Prevalence and epidemiological characteristics of urolithiasis in Japan: national trends between 1965 and 2005. Urology 2008; 71: $209 \mathrm{e} 13$. 
[29] Frank M, De Vries A, Atsmon A, Lazebnik J, Kochwa S. Epidemiological investigation of urolithiasis in Israel. J Urol 1959; 81: 497e505.

[30] Sorokin I, Mamoulakis C, Miyazawa K, Rodgers A, Talati J, Lotan Y. Epidemiology of stone disease across the world. World J Urol 2017; 35: 1301e20.

[31] Abdel-Halim RE, Al-Hadramy MS, Hussein M, Baghlaf AO, Sibaai AA, Noorwali AW, et al. The prevalence of urolithiasis in the western region of Saudi Arabia: a population study. In: Walker VR, Sutton RAL, Cameron ECB, Pak CYC, Robertson WG, editors. Urolithiasis. Boston, MA: Springer; 1989. p. $711 \mathrm{e} 2$.

[32] Ahmed, A., Jhamaria, P. eta!. Diurnal changes in urinary chemistry of normal Muslim subjects during fast. In: Walker yR., Sutton, R. A. L., Cameron, E. C. B. Pak C. Y. C. and Robertson WG. (eds). Urolithiasis. New York, Plenum Press, 1989, pp. 767-8. 